\title{
Scaling the Stiffness, Strength, and Toughness of Ceramic- Coated Nanotube Foams into the Structural Regime
}

\author{
Anna Brieland-Shoultz, Sameh Tawfick, Sei Jin Park, Mostafa Bedewy, \\ Matthew R. Maschmann, Jeffery W. Baur, and A. John Hart**
}

Natural materials such as bone and tooth achieve precisely tuned mechanical and interfacial properties by varying the concentration and orientation of their nanoscale constituents. However, the realization of such control in engineered foams is limited by manufacturing-driven tradeoffs among the size, order, and dispersion uniformity of the building blocks. It is demonstrated how to manufacture nanocomposite foams with precisely controllable mechanical properties via aligned carbon nanotube (CNT) growth followed by atomic layer deposition (ALD). By starting with a low density CNT forest and varying the ALD coating thickness, we realize predictable $\approx 1000$-fold control of Young's modulus ( $14 \mathrm{MPa}$ to $20 \mathrm{GPa}$, where $E \sim \rho^{2.8}$ ), ultimate compressive strength $(0.8 \mathrm{MPa}$ to $0.16 \mathrm{GPa})$, and energy absorption ( 0.4 to $400 \mathrm{~cm}^{-3}$ ). Owing to the continuous, long CNTs within the ceramic nanocomposite, the compressive strength and toughness of the new material are 10-fold greater than commercially available aluminum foam over the same density range. Moreover, the compressive stiffness and strength equal that of compact bone at $10 \%$ lower density. Along with emerging technologies for scalable patterning and roll-to-roll manufacturing and lamination of CNT films, coated CNT foams may be especially suited to multifunctional applications such as catalysis, filtration, and thermal protection.

\section{Introduction}

Design of the hierarchical structure and composition of cellular materials offers a versatile means to tune mechanical properties, such as Young's modulus, strength, and toughness.

\author{
A. Brieland-Shoultz, ${ }^{[+]}$Dr. S. Tawfick, ${ }^{[+]}$S. J. Park, ${ }^{[+]}$ \\ M. Bedewy \\ Department of Mechanical Engineering \\ University of Michigan \\ 2350, Hayward Street, Ann Arbor, MI 48109, USA \\ Dr. M. R. Maschmann, Dr. J. W. Baur \\ Air Force Research Laboratory \\ Materials and Manufacturing Directorate \\ AFRL/RX, Wright Patterson Air Force Base \\ $\mathrm{OH} \mathrm{45433,} \mathrm{USA}$ \\ Dr. S. Tawfick, Prof. A. J. Hart \\ Department of Mechanical Engineering \\ Massachusetts Institute of Technology \\ 77 Massachusetts Ave, Cambridge, MA 02139, USA \\ E-mail: ajhart@mit.edu \\ ${ }^{[+]}$These authors contributed equally.
}

DOI: 10.1002/adfm.201400851
Cellular materials can also achieve unique combinations of properties, while maintaining large surface areas and low mass density. For example, the mechanical properties of metallic foams enable their use for energy absorption in consumer goods packaging and composite sandwich structures, and their porosity enables use in battery and capacitor electrodes. ${ }^{[1]}$ Ceramic foams are widely used as mechanical, thermal and acoustic insulators, for flow filtration and regulation, and as catalyst supports. ${ }^{[2]}$ Many natural materials use analogous design principles; for example, the exquisite structure-function relationship of bone spans from stiff and dense cortical load bearing bone to highly porous cancellous bone where haematopoiesis occurs. ${ }^{[3]}$ Further, the geometric and compositional hierarchy of soft and hard constituents result in the high toughness of bone at low mass density. ${ }^{[4]}$

Recently, micro- and nanofabrication methods such as photo, X-ray, and interference lithography have been applied to prototype micro- and nanoscale foams with unique cell geometries and hierarchical structures. ${ }^{[5]}$ For example, fabrication of epoxy lattices by interference lithography enabled a priori tuning of the cell size in the sub-micron regime. These foams showed a classical power-law relationship between Young's modulus and relative density $\left(\mathrm{E} \sim\left[\rho / \rho_{\mathrm{s}}\right]^{\mathrm{n}}\right)$, with $n=1.26$; at $\rho_{\mathrm{r}}=0.5$ the energy absorption reached $4 \mathrm{~J} \mathrm{~cm}^{-3}$ at strain $<0.25 .^{[5]}$ Use of sacrificial polymer templates to make hollow tube metallic microlattices resulted in a foam with record low density $\left(\rho_{\mathrm{r}}=\rho / \rho_{\mathrm{s}}=2 \times 10^{-4}, \rho \sim 1 \mathrm{mg} \mathrm{cm}^{-3}\right)$ and high recoverability, but low Young's modulus $(E \sim 550 \mathrm{kPa}){ }^{[6]}$ In this case, due to the hollow structure of the metal truss members, the relationship between modulus and relative density followed a power law with $n=2$. This contrasts most fibrous nanoscale aerogels and foams, having $n=2-3$, which is attributed to low connectivity between the constituent struts. ${ }^{[7]}$ When comparing foam materials, a higher power law exponent results in a relatively larger change in $E$ for the same change in density.

While these methods have enabled exploration of new design and property regimes for engineered foams, their manufacturing cost and complexity currently prohibit them from scaling to large quantities that can be incorporated in macroscale engineering systems. In contrast, most industrially manufactured 
foams have isotropic and random cell geometry. Closed cell metallic and polymer foams are usually manufactured by gas injection into melts, while open cell metallic foams are usually made by vapor deposition or electrodeposition of metal precursors on polymer scaffolds. Porous metallic and ceramic materials can also be manufactured by compaction and sintering of powders. ${ }^{[8]}$

Directed growth and self-organization of nanostructures is emerging as an attractive and potentially scalable route to create hierarchical materials having both composition- and geometryderived mechanical properties. Carbon nanotubes (CNTs) have outstanding properties including high Young's modulus, strength, conductivity, and thermal stability. Moreover, CNTs can be manufactured in large quantities by cost-effective chemical vapor deposition (CVD) methods, ${ }^{[9]}$ and assembled, either during or after CVD, into ordered forms such as vertically aligned "forests", yarns, and sheets. ${ }^{[10]}$ While as-grown CNT forests have high compressibility ${ }^{[11,12]}$ and have shown promise as energy-dissipating surfaces and interlayers, ${ }^{[11,13]}$ CNT forests and isotropic foams made from $\mathrm{CNTs}^{[13]}$ have low density usually in the range of $10-100 \mathrm{~kg} \mathrm{~m}^{-3}$ or $\rho / \rho_{\mathrm{s}}=0.5-5 \%$ (considering $\rho_{\mathrm{s}}$ to be equal to solid graphite at $2200 \mathrm{~kg} \mathrm{~m}^{-3}$ ).

Therefore, it remains an opportunity to explore how selfassembly of CNTs, in combination with conformal coating methods, ${ }^{[14]}$ can be used to create bulk materials with efficient and widely tunable properties, and to compare these properties to commercially available structural materials. In this study, we show that nanoscale coating of a ceramic onto clean CNT forests enables unprecedented tuning of Young's modulus, strength, and toughness, without changing the structure or composition of the nanoporous material.

\section{Results}

\subsection{Fabrication and Compression Testing of Ceramic-Carbon Nanotube Foams}

First, CNT forests, comprising vertically aligned multi-wall CNTs, were synthesized from a supported metal catalyst film (see Experimental Section) by atmospheric pressure chemical vapor deposition (CVD). ${ }^{[15]}$ Then, $\mathrm{Al}_{2} \mathrm{O}_{3}$ was deposited by atomic layer deposition (ALD), conformally coating the CNTs and CNT bundles within the forest, resulting in a nanoporous composite with ceramic-carbon core-shell structural members. The thickness of $\mathrm{Al}_{2} \mathrm{O}_{3}$ on the CNTs was controlled by the number of ALD process cycles. During each cycle of ALD, the precursors $\left(\mathrm{Al}\left(\mathrm{CH}_{3}\right)_{3}\right.$ and $\left.\mathrm{H}_{2} \mathrm{O}\right)$ are sequentially introduced in two half-reaction stages, and the thickness during each cycle is self-limiting to approximately $1.3 \AA .^{[16]}$

The change in morphology of the CNT forest due to $\mathrm{Al}_{2} \mathrm{O}_{3}$ coating is shown in Figure $1 \mathrm{a}-\mathrm{c}$. First, $\mathrm{ALD} \mathrm{Al}_{2} \mathrm{O}_{3}$ nucleation occurs preferentially at surface defects on the CNTs (Figure SI1) ${ }^{[17]}$ and at contact points among CNTs. After nucleation, the coating grows to fully cover the individual CNTs, and in some cases bundles of CNTs. After a certain thickness the coated CNTs and bundles coalesce. Judging from SEM images of the forest sidewalls, this coalescence begins at coating thickness of approximately $30 \mathrm{~nm}$, compared to the average CNT-CNT spacing of a

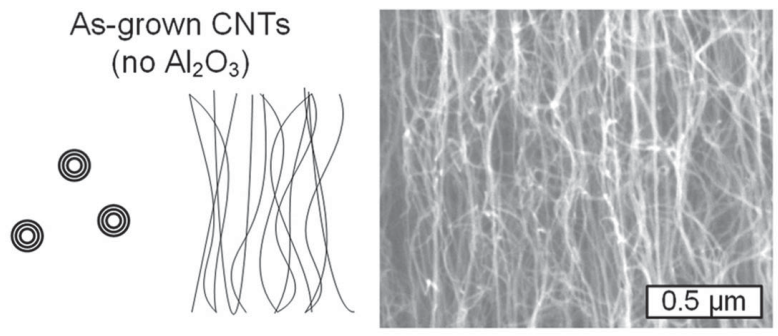

b
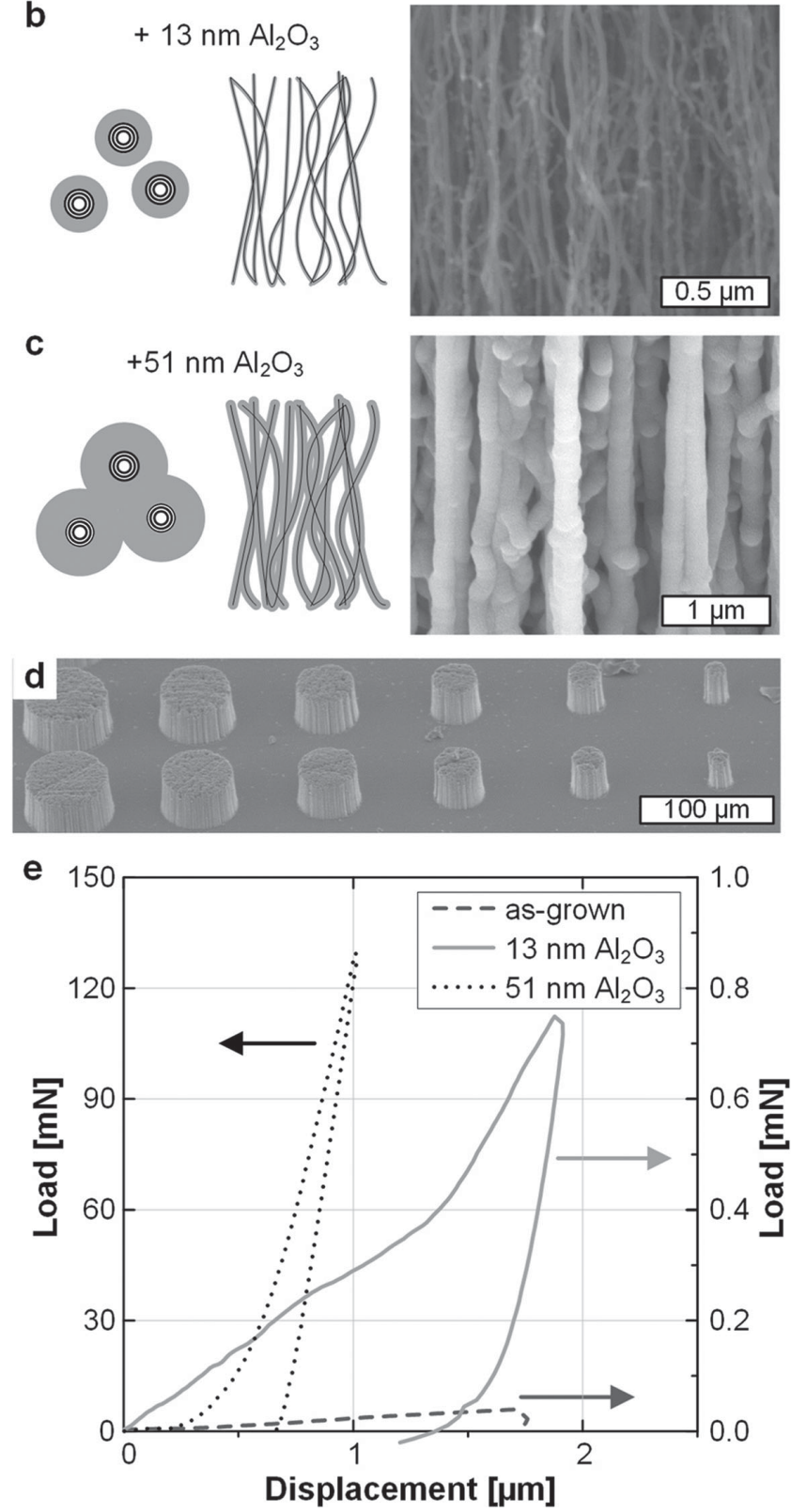

Figure 1. Morphology, structure and compression testing of $\mathrm{Al}_{2} \mathrm{O}_{3}$-CNT foam. a) Schematic and scanning electron microscope (SEM) image of as-grown vertically aligned CNTs ("forest"). CNT forest conformally coated with b) $13 \mathrm{~nm}$ thick and c) $51 \mathrm{~nm}$ thick $\mathrm{Al}_{2} \mathrm{O}_{3}$ by atomic layer deposition (ALD). d) $\mathrm{Al}_{2} \mathrm{O}_{3}$-coated CNT micropillars fabricated for micro-compression testing. e) Load-displacement measurement of micropillars $(D=30 \mu \mathrm{m})$, having nanoscale morphology as shown in $(a-c)$. 
approximately $50 \mathrm{~nm}$ (number density $\approx 3 \times 10^{10} \mathrm{~cm}^{-2}$ ). The local CNT spacing and density represent a distribution, determined by the waviness and bundling of the CNTs which can be approximated by their average orientation angle as discussed later.

CNT micropillars, made using a lithographically patterned catalyst, were used to study the scaling of mechanical properties with the number of ALD cycles, and to relate the mechanics to the penetration depth of ALD coating. Test samples were fabricated with arrays of CNT micropillars having radii ranging from 10-35 $\mathrm{m}$ (Figure 1d). The micropillars were tested in quasistatic axial compression using a nanoindenter with a cylindrical flat diamond tip (50 $\mu \mathrm{m}$ radius). The Young's modulus was obtained from the unloading slope in continuous modulus mode (10 nm oscillations at $50 \mathrm{~Hz}$ ) at a compressive pre-strain of 0.05 (approximately $2 \mu \mathrm{m}$ compression of the micropillar).

Load-displacement curves of individual $15 \mu \mathrm{m}$ radius $\mathrm{Al}_{2} \mathrm{O}_{3^{-}}$ CNT micropillars with $30 \mu \mathrm{m}$ height, with coatings of 0,100 , and 1000 ALD cycles, are compared in Figure 1e. The load capacity of the pillars increases from $<0.1 \mathrm{mN}$ for the uncoated (bare CNT) pillar, to $0.7 \mathrm{mN}$ with $13 \mathrm{~nm}$ coating (100 ALD cycles), and $130 \mathrm{mN}$ with $51 \mathrm{~nm}$ coating (1000 cycles). As shown in Figure 2c for $\mathrm{R}_{\text {pillar }}=15 \mu \mathrm{m}$, the Young's modulus scales from $14.5 \mathrm{MPa}$ for uncoated CNTs to $24.5 \mathrm{GPa}$ with $51 \mathrm{~nm} \mathrm{Al} \mathrm{O}_{3}$ coating.

\subsection{Structural Characterization of Coating Morphology}

To further understand the structure-property relationship via ALD coating, we measured the coating thickness and the density evolution per ALD cycle. To determine the penetration depth, we coated patterned CNT forest "line" features and found, as shown in Figure 3a, that the penetration depth is approximately 5-7 $\mu \mathrm{m}$. To overcome this limitation and demonstrate the scaling on large sample areas, perforated "honeycomb" patterns (Figure 3b) with $10 \mu \mathrm{m}$ spacing between holes were synthesized. The perforations enabled uniform ALD coating throughout the CNT forest, and therefore were used for subsequent characterization.

Transmission SAXS was then used to characterize the morphology of the as grown and $\mathrm{Al}_{2} \mathrm{O}_{3}$-coated CNTs by placing the honeycomb film sample in the beamline path of a synchrotron X-ray beam and collecting the scattered X-rays on an area detector (Figure 4, Figure S1, Supporting Information). ${ }^{[18,19]}$ As in our previous work, ${ }^{[19]}$ the statistical distribution of outer diameters for both coated and uncoated CNTs was obtained by fitting a mathematical model of polydisperse core-shell cylinders to line-scans of scattering intensity. The linescans are obtained by integration of the scattered intensities within a sector of $+/-10^{\circ}$ about the axis of maximum intensity on the $2 \mathrm{D}$ scattering pattern, as shown in Figure S1, Supporting Information.

This method determines the average outer and inner radii of the bare CNTs as 5.0 and $3.5 \mathrm{~nm}$, respectively. As seen in Figure $4 \mathrm{a}$, the peak corresponding to the scattering from the population of $\mathrm{Al}_{2} \mathrm{O}_{3}$-coated CNTs shifts to a lower value on the $\mathrm{x}$-axis with increasing coating thickness. Therefore, coating leads to a significant increase in the size of the scatters, which is quantified by fitting the data for coated samples with a core-shell scattering model. Analysis of the coated samples gives average coating thickness of $8.5,14.5$ and $26.7 \mathrm{~nm}$ for 50 , a
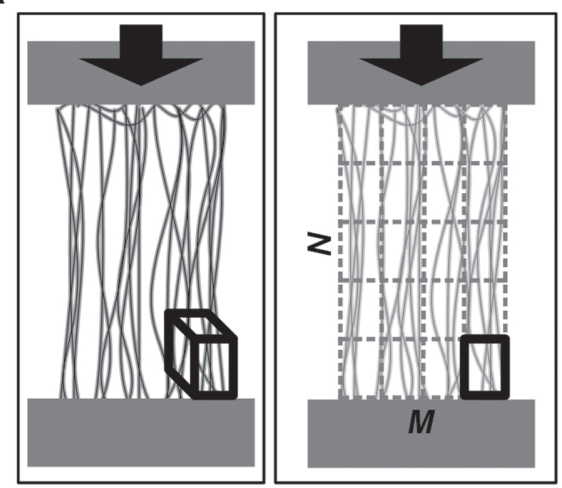

b
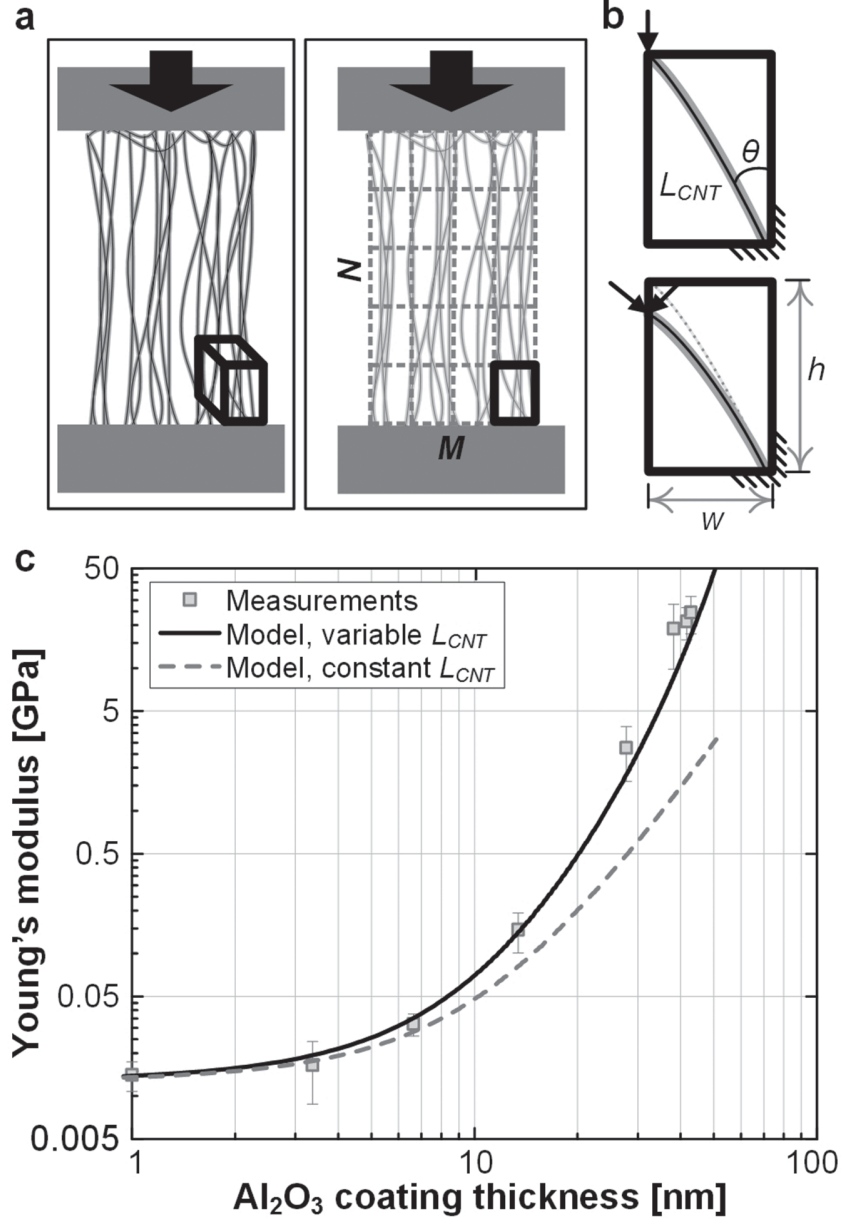

d
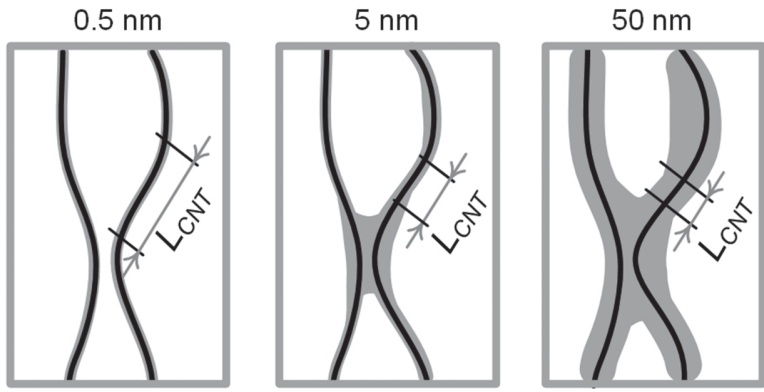

Figure 2. Unit cell model to predict compressive stiffness of $\mathrm{Al}_{2} \mathrm{O}_{3}$ CNT foams, based on bending deformation of angled core-shell beams. a) Schematic of composite micropillar, and representative decomposition into NxM unit cells. b) Schematic of an individual unit cell showing a CNT beam in bending, with load decomposed into parallel and perpendicular components. c) Comparison of measurements and model of the scaling of Young's modulus with the $\mathrm{Al}_{2} \mathrm{O}_{3}$ coating thickness. d) Schematics of the evolution of coating morphology, indicating reduction of the characteristic beam length which modifies the effective unit cell geometry.

100 and 200 cycles of ALD, (Figure 4b). For 100 and 200 cycles, a second peak on the SAXS linescans is seen at a $q$ value higher than the form-factor peak. This peak could arise from the observed roughening of the $\mathrm{Al}_{2} \mathrm{O}_{3}$ layer at the greater coating thickness (Figure S1c, Supporting Information).

We also estimated the average coating thickness by measuring the weight of the samples before and after ALD coating. 

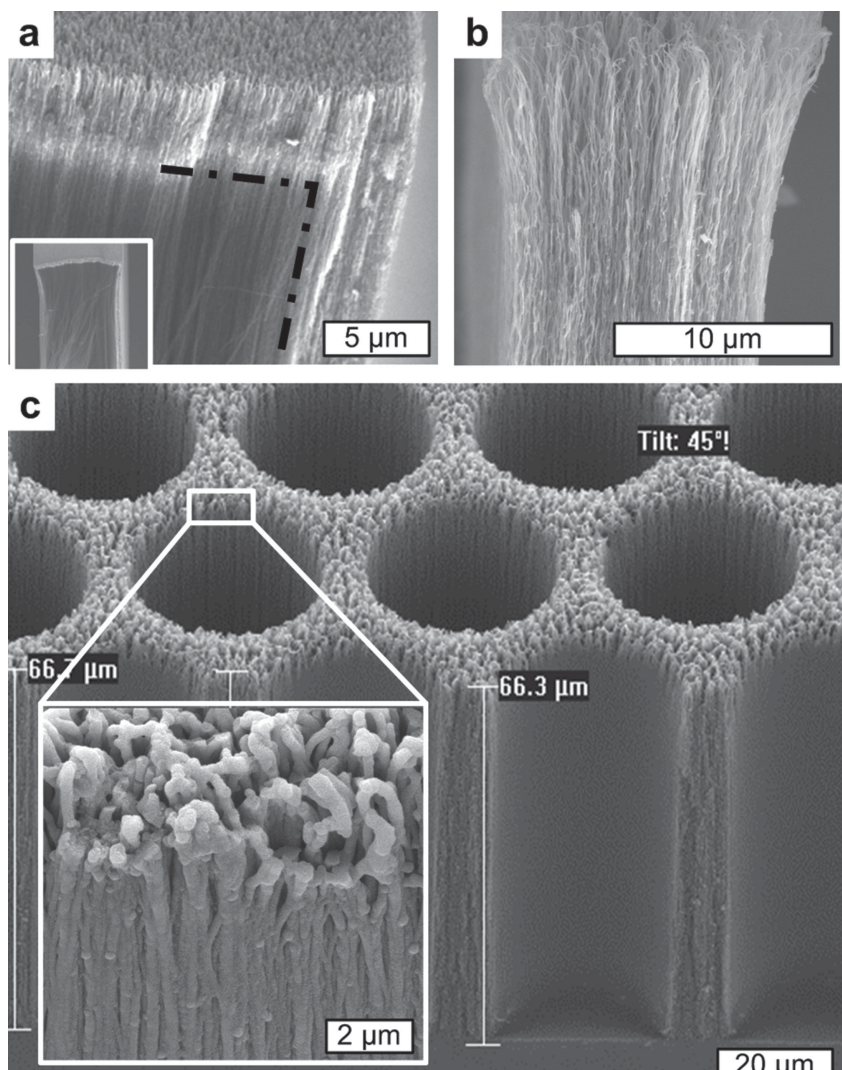

$2 \mu \mathrm{m}$
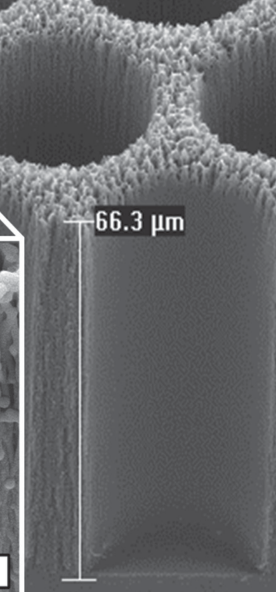
$66.3 \mu \mathrm{m}$
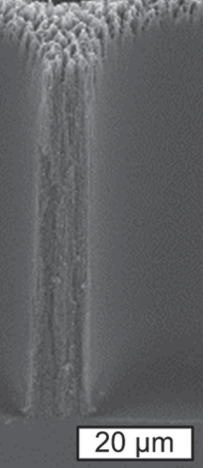

Figure 3. Penetration depth and hierarchical design of $\mathrm{Al}_{2} \mathrm{O}_{3}-\mathrm{CNT}$ composite films. a) Cross section SEM of cleaved microwall ( $100 \mu \mathrm{m}$ width) showing the coating penetration depth (bright areas) from the top and the sides of the micropillar. b) Cross section SEM of cleaved microwall (10 $\mu \mathrm{m}$ width) showing uniform coating throughout the thickness. c) Hierarchical honeycomb pattern with $10 \mu \mathrm{m}$ wall thickness designed to achieve uniform scaling of ALD coating over large areas.

We found a sub-linear relationship between mass and the number of cycles, showing that the deposited thickness per ALD cycle is affected by the ability of the precursors to diffuse into the CNT forest; this reduces as the porosity of the sample decreases when subject to multiple cycles. We therefore constructed a model where the pore size is decreased with each subsequent cycle. We found (Figure $4 \mathrm{~b}$ ) that the best fit to the SAXS and weight measurements corresponds to a decrease of effective diffusion coefficient of vapor phase precursors in porous media by $0.5 \%$ per cycle, starting at the $140^{\text {th }}$ cycle of ALD coating. We did not consider the increase in available area due to the increase in effective diameter, which is counteracted by the coalescence of coated CNTs as the coating thickness increases. Improved uniformity of coating could likely be achieved by increasing the precursor cycle duration.

As a result of diffusion-limited coating, the Young's modulus of the $\mathrm{Al}_{2} \mathrm{O}_{3}$-CNT composites depended strongly on the micropillar diameter. The full matrix of compression tests performed with pillars having 10-35 $\mathrm{mm}$ radius, at each coating thickness, is summarized in Figure S3, Supporting Information. Here, modulus is inversely proportional to pillar diameter, as the reinforcement of larger pillars is limited by ALD penetration and therefore the final composite pillar is a reinforced shell
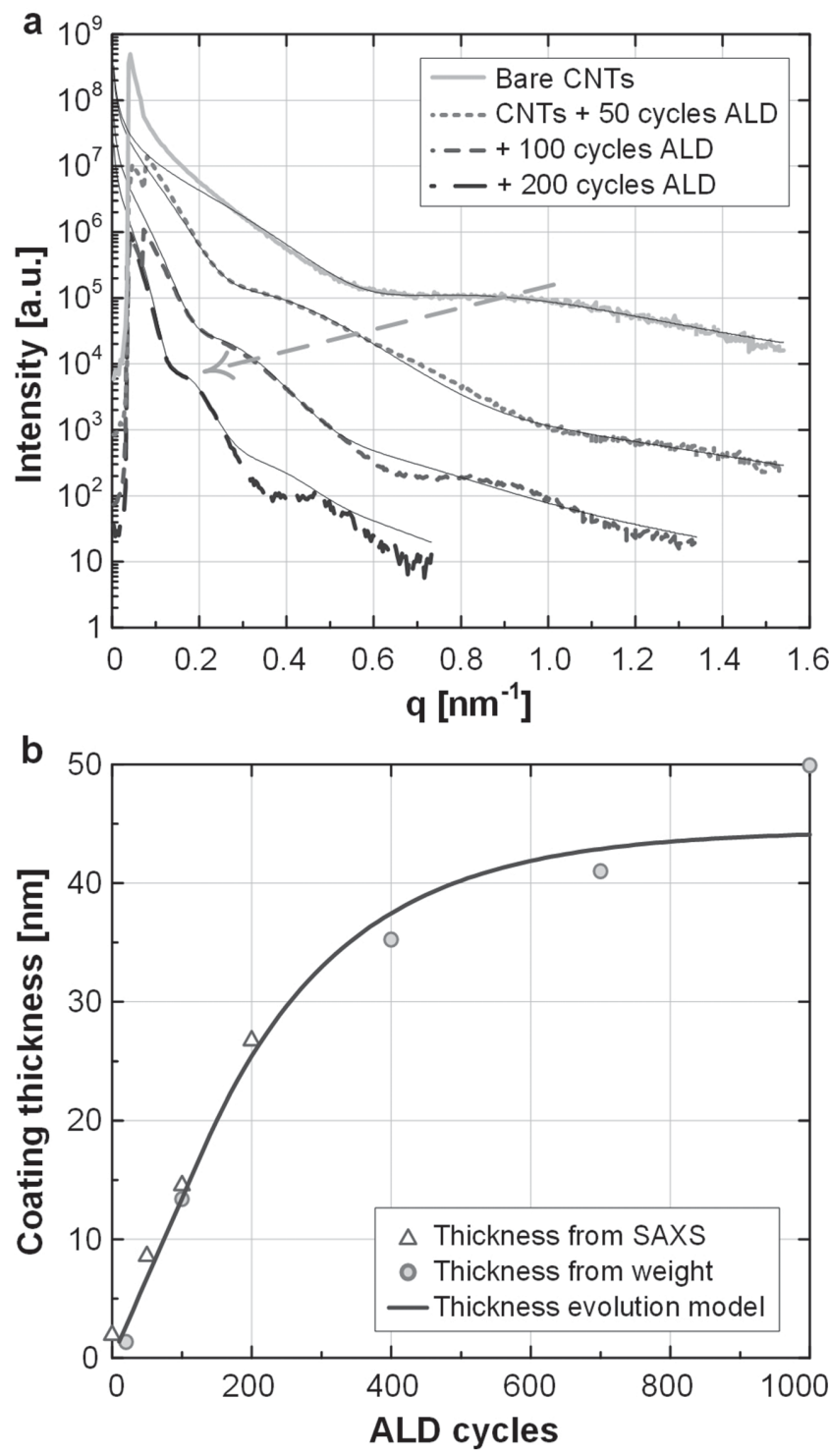

Figure 4. Characterization of core-shell CNT- $\mathrm{Al}_{2} \mathrm{O}_{3}$ morphology by Small Angle X-ray Scattering (SAXS) spectra of "honeycomb" pattern films. a) I-q curves obtained from integration of SAXS images, showing evolution of primary scattering peak corresponding to population of cylindrical nanostructures. b) $\mathrm{Al}_{2} \mathrm{O}_{3}$ coating thickness obtained by fitting SAXS data with mathematical model, compared to measurements derived from weight change of each sample after ALD. Curve fit to (b) represents diffusion-limited infiltration of the CNT forest by the ALD coating precursors.

surrounding a soft core of uncoated CNTs. These trends, and specifically the size-dependent modulus of non-coated pillars, are also attributed to size-dependent growth effects on the density of CNTs within the forest. This topic is currently under separate study in our group. ${ }^{[20]}$

\subsection{Model of Cellular Mechanics}

We now present a model of the Young's modulus of the $\mathrm{Al}_{2} \mathrm{O}_{3}$ CNT composites under quasi-static loading. First, as verified 
by SAXS, we note that ALD coating creates a nanoporous composite where the load-bearing elements are nanoscale core-shell beams. These beams are loaded primarily in bending when the structure is loaded in compression. Previous work using in situ SEM digital image correlation has shown that the CNT-CNT contact points within an uncoated CNT forest do not slip upon compressive loading below the failure threshold of approximately 5\% local strain. ${ }^{[21]}$ As a result, uncoated CNT forests can be approximated as open-cell foams where the deformation of individual CNTs and bundles represent the cell walls (struts).

We approximate the nanoporous network of interconnected wavy $\mathrm{Al}_{2} \mathrm{O}_{3}$-CNT beams as an effective cellular solid with rectangular unit cell geometry (Figure 2a). We consider the CNTs as an array of beams loaded simultaneously in bending and compression, ${ }^{[22]}$ having identical diameter and length. We further use SAXS to determine the average orientation angle of each CNT with respect to the vertical axis $\left(\theta=40^{\circ}\right.$, with a random distribution of azimuthal angles), ${ }^{[23]}$ giving the unit cell aspect ratio $\left(H_{\mathrm{CNT}} / W_{\text {cell }}=1.67\right)$. Although the CNT alignment and therefore the orientation are known to vary throughout the forest due to changes in the CNT density, here we use a single average value to represent the effective properties.

With this information, we first calculate the effective unit cell size, where each unit cell contains one angled CNT having length $\left(L_{\mathrm{CNT}}\right)$ and inclination angle $(\theta)$. This is an approximation for the real structure of the forest, which certainly contains a distribution of CNT angles, effective lengths, and effective unit cell sizes. The stiffness of a unit cell $k_{\mathrm{CNT}}$ is represented by a cantilever beam in combined axial compression and endloaded cantilever beam bending (Figure 2a,b)

$\frac{1}{k_{C N T}}=\frac{\sin ^{2} \theta}{E_{C N T} I_{C N T}} L_{C N T}^{3}+\frac{\cos ^{2} \theta}{E_{C N T} A_{C N T}} L_{C N T}$

Here, $E_{\mathrm{CNT}}$ is the Young's modulus (1 TPa, ${ }^{[24]}$ based on the wall area only), and the cross-sectional area of the CNT $\left(A_{\mathrm{CNT}}\right)$ and second moment of area $\left(I_{\mathrm{CNT}}\right)$ are both determined from the average CNT outer and inner diameters measured by SAXS. The total stiffness of the foam is therefore related to the unit cell stiffness by the assembly of $M$ (across the horizontal cross-section) by $N$ (along the height) unit cells (Figure 2a) into a cylindrical solid representing a micropillar,

$k_{\text {assembly }}=\frac{\pi E_{\text {pillar }} R_{\text {pillar }}^{2}}{H_{\text {pillar }}}=\frac{M k_{C N T}}{N}$

We derive $L_{\mathrm{CNT}}=210 \mathrm{~nm}$, as well as $N$ and $M$, which give $h=$ $160 \mathrm{~nm}$ and $w=95 \mathrm{~nm}$.

We now predict the modulus of the composite assuming uniform coating of the slanted CNTs within each unit cell, causing a proportional contribution of each cell to the overall stiffness of the micropillar structure. Therefore, we then scale the Young's modulus of the unit cell, using a core-shell beam model where the $\mathrm{Al}_{2} \mathrm{O}_{3}$ shell thickness is determined by the number of ALD cycles. The $\mathrm{Al}_{2} \mathrm{O}_{3}$ Young's modulus is taken to be $180 \mathrm{GPa} \cdot{ }^{[25]}$

$(E I)_{\text {composite }}=E_{C N T} I_{C N T}+E_{A l 2 O 3} I_{A l 2 O 3}$
The comparison between the measured compressive modulus and the predicted modulus from the unit cell model is shown in Figure 2c. For coating thickness below $\sim 5 \mathrm{~nm}$, the effective spring model with constant $L_{\text {CNT }}$ closely predicts the experimentally measured scaling of elastic modulus with coating thickness. As a result, we conclude that the primary mechanism of axial deformation of the foam is bending of the individual nanoscale elements. However, to our surprise, assuming constant $L_{\mathrm{CNT}}$ does not accurately predict the measured stiffness at coating thickness $>10 \mathrm{~nm}$. This is because the length of the slanted core-shell beams decreases as more coating is deposited, causing additional junctions to form between nearby CNTs whose gaps are filled by the thicker coating. To adapt the model to the morphology evolution, we iteratively update the characteristic length,

$L_{C N T \mid n+1}=L_{C N T \mid n}-2 t_{n+1}$

Here, $n$ and $n+1$ are the ALD cycle numbers, and $t$ is the $\mathrm{Al}_{2} \mathrm{O}_{3}$ deposition thickness during the cycle, which is determined from the SAXS and density analysis. This is schematically shown in Figure 2 d. The variable $L_{\mathrm{CNT}}$ model accurately predicts the modulus scaling at large coating thickness, up to the maximum coating of $51 \mathrm{~nm}$. At this point, the increased reinforcement due to coalescence of individual CNTs and bundles (as seen in Figure 1c) changes the effective unit cell height, thus increasing load transfer by compression of the structural members rather than bending. Moreover, further increase in density of the composite is limited, as we suspect the exterior voids are fully closed and the coating precursors can no longer penetrate uniformly and deeply into the foam. As a result, we calculated the Young's modulus to represent ALD penetration depth of $5 \mu \mathrm{m}$ from the outside surfaces of the micropillar. In Figure S4 we provide plots showing the dependence of Young's modulus on the ALD penetration depth.

While penetration of larger micro-scale geometries is limited under the present ALD conditions, the perforated honeycomb design (Figure 3c) shows potential to achieve uniform composite properties over large areas, as it enables uniform infiltration of the coating precursors. A honeycomb CNT forest with 1000 cycles ALD $\mathrm{Al}_{2} \mathrm{O}_{3}$ has $E=38.3 \pm 3.7 \mathrm{GPa}$ based on the solid area of the cross-section. Nevertheless, future study should focus on optimizing the depth and uniformity of infiltration and coating, as determined by the deposition temperature, pressure, and the precursor chemistry.

\section{Discussion}

The $\mathrm{Al}_{2} \mathrm{O}_{3}$-CNT foams also withstand large deformations at high stresses before failure, and therefore have exceptional toughness. In Figure 5 we show the measured stress versus energy absorbed for foams with selected coating thicknesses. The data here is obtained by integrating the area under the quasi-static stress-strain curves of micropillars compressed to large strains. We note three regions, as compressive strain increases: 1) a linear regime where the energy absorbed is proportional to the applied stress; 2) a steep increase in energy absorbed, corresponding to the plateau in the stress-strain 
a

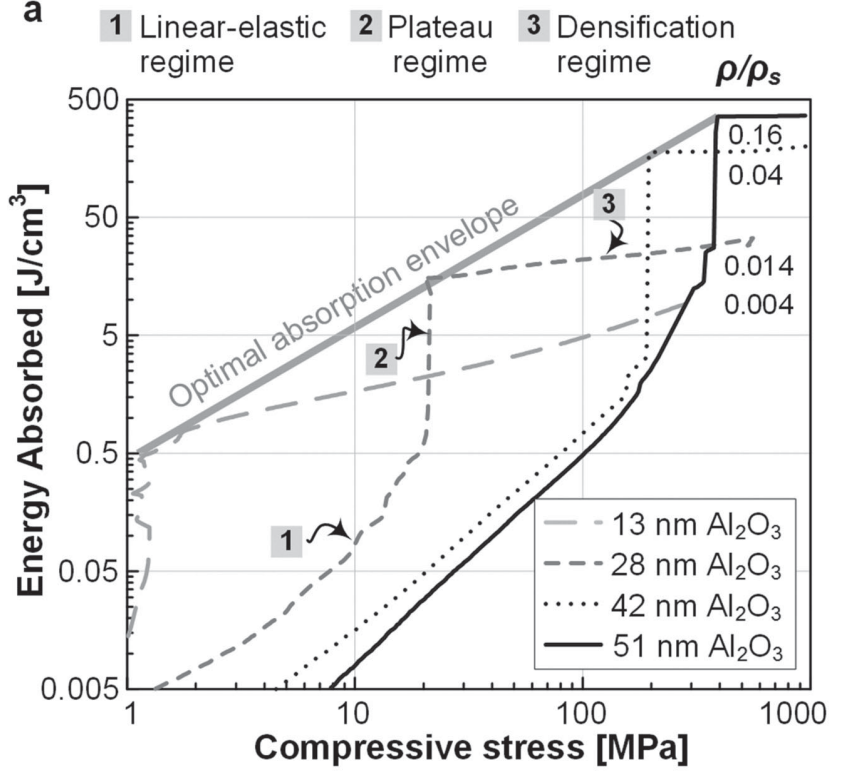

b

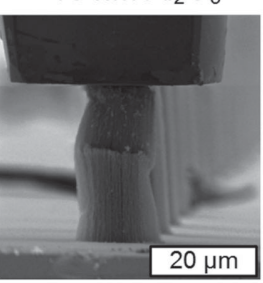

$28 \mathrm{~nm} \mathrm{Al}_{2} \mathrm{O}_{3}$
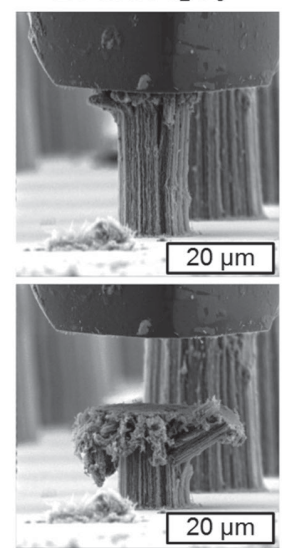

$42 \mathrm{~nm} \mathrm{Al}_{2} \mathrm{O}_{3}$

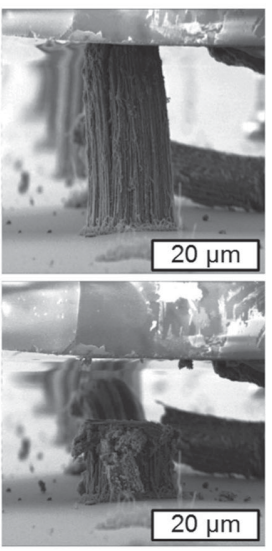

Figure 5. Toughness of $\mathrm{Al}_{2} \mathrm{O}_{3}$-CNT foams. a) Strain energy absorbed versus stress for micropillars with different $\mathrm{Al}_{2} \mathrm{O}_{3}$ coating thickness, showing the transition from linear elastic compression to the plateau (increase in strain without increase in stress) and the densification regimes (increase in stress without increase in strain). b) SEM images from in situ compression testing showing the failure modes for coated CNT pillars at high strains: buckling for $13 \mathrm{~nm}$ thick coatings and cracking for 28 and $42 \mathrm{~nm}$ thick coatings. Top row shows micropillars during compression, and bottom row shows the same respective test after unloading.

curve; and 3) densification as the material fails. Large energy absorption, characterized by an increase in total energy stored due to deformation without much increase in the resultant stress, occurs until the vertical tip of each of these curves before the slope is decreased due to the small resultant strain at the foam densification regime (3). This indicates that most of the energy absorbed is due to the large deformations of the individual cells, a favorable property for structural foams.

The high toughness indicates that the CNTs, even at very low weight\% ( $\approx 2.5 \mathrm{wt} \%$ CNTs after 1000 cycles ALD), bridge cracks in the $\mathrm{Al}_{2} \mathrm{O}_{3}$ foam that form upon compressive loading. This prevents catastrophic fracture until a very large strain, and hence results in large energy absorption. We believe that rapid

crack propagation is mitigated due to the collective buckling of the $\mathrm{Al}_{2} \mathrm{O}_{3}$-CNT struts held in proximity by van der Waals interactions, or in some areas by thin ceramic junctions. In contrast, classical open cell (e.g., Al) foams have continuous struts connected at the junctions and spanning the cells. Thus, at the same density, classical foams require larger forces to buckle the members, and exhibit a narrower plateau in the stress-strain curve than observed for the $\mathrm{Al}_{2} \mathrm{O}_{3}$ - $\mathrm{CNT}$ foams.

The deformation and failure mechanisms are further understood by examining in situ SEM videos of micropillars under compression (Figure 5b, Videos S1-S3, Supporting Information). In these videos and the accompanying stress-strain curves, we find that foams with approximately $10 \mathrm{~nm} \mathrm{Al} \mathrm{O}_{3}$ coating fully recover large compressive strains, and exhibit significant hysteresis (i.e., material damping). We suspect this is due to the reinforcement provided by the $\mathrm{Al}_{2} \mathrm{O}_{3}$ coating, enabling the elastic energy to reversibly overcome the stiction of the struts due to van der Waals forces, while remaining flexible to prevent fracture at large global strains. At thinner coatings, the applied stress is not recovered as stiction dominates, whereas at thicker coatings, fracture occurs, resulting in permanent deformation albeit with very high toughness. The role of the coating thickness in joining and bundling CNTs into a hierarchical nanocomposite structure is evident by comparing the fracture behavior of pillars in the thick coating regime. The pillar with $28 \mathrm{~nm}$ coating splits outward as fracture propagates parallel to the CNTs, while the pillar with $43 \mathrm{~nm}$ coating initially cracks then crushes uniformly under uniaxial compression.

In summary of the above data, we achieve tuning of the elastic modulus by more than 1000 -fold by simply varying the thickness of the $\mathrm{Al}_{2} \mathrm{O}_{3}$ ALD coating. The achieved values (Figure 6a) range from (on the low end) those typical of uncoated CNT foams and other low-density nanostructured foams, to (on the high end) those known for structural aluminum honeycombs having millimeter-scale cell size. ${ }^{[26]}$ Moreover, the strength of our $\mathrm{Al}_{2} \mathrm{O}_{3}$-CNT composites, which is determined as the maximum stress before the slope of the loading curve decreases abruptly (Figure 6b, Figure S5), is 10-fold higher than isotropic aluminum foams having the same density of $\rho=1000 \mathrm{~kg} \mathrm{~m}^{-3}$, and at this point is comparable to compact bone which has 2-fold higher density $\left(\rho=2000 \mathrm{~kg} \mathrm{~m}^{-3}\right){ }^{[3]}$ The modulus that we achieve also exceeds that measured for composites of mechanically densified CNT forests with aerospace grade epoxy, where $\mathrm{E}=9 \mathrm{GPa}$ is achieved at $20 \% \mathrm{CNT}$ volume fraction. ${ }^{[27]} \mathrm{As}$ stated before, $E$ is defined as the slope of the unloading curve, and $\sigma_{\mathrm{y}}$ is defined as the location on the stress-strain curve where the slope starts to decrease after the initial linear-elastic regime.

Comparing the scaling behavior to conventional open cell foams, we note that the Young's modulus and strength of the $\mathrm{Al}_{2} \mathrm{O}_{3}$-CNT composite scale as $E \sim \rho^{2.8}$ and $\sigma_{\mathrm{y}} \sim \rho^{2.9}$ (Figure 6). Ideal bend-dominated open-cell foams such as open-cell polymer foams, ${ }^{[28]}$ and aluminum honeycombs ${ }^{[29]}$ scale as $E \sim \rho^{2}$ and $\sigma_{\mathrm{y}}$ $\sim \rho^{2}$. The modulus scaling of our ALD-coated CNTs incidentally resembles that of of isotropic CNT foams, ${ }^{[30]}$ CNT aerogels, ${ }^{[31]}$ and Si aerogels ${ }^{[32]}$ which scale as $\approx \rho^{3}$, and commonly attributed to the interdependence of strut thickness and cell size. This explains the discrepancy between the measured $E$ and the constant length strut analytical model (Figure 2c). On the other hand, ultralight open-cell foams such as Ni-P microlattices ${ }^{[6]}$ show $\mathrm{E} \sim \rho^{2}$ because 
$\diamond \mathrm{CNT}-\mathrm{Al}_{2} \mathrm{O}_{3}$ [this study]

$\square$ CNT foam [Worsley et al. 2009]

$\square$ CNT foam [Worsley et al. 2009]

O Al foam (Fraunhofer)

[Andrews et al. 1999]

$\triangle \mathrm{Al}_{2} \mathrm{O}_{3}$ hydrogel

$\triangle \mathrm{Si}$ aerogels

- Al foam (Alcan) [Andrews et al. 1999] $\triangle$ PDMS $\quad$ XSU-8
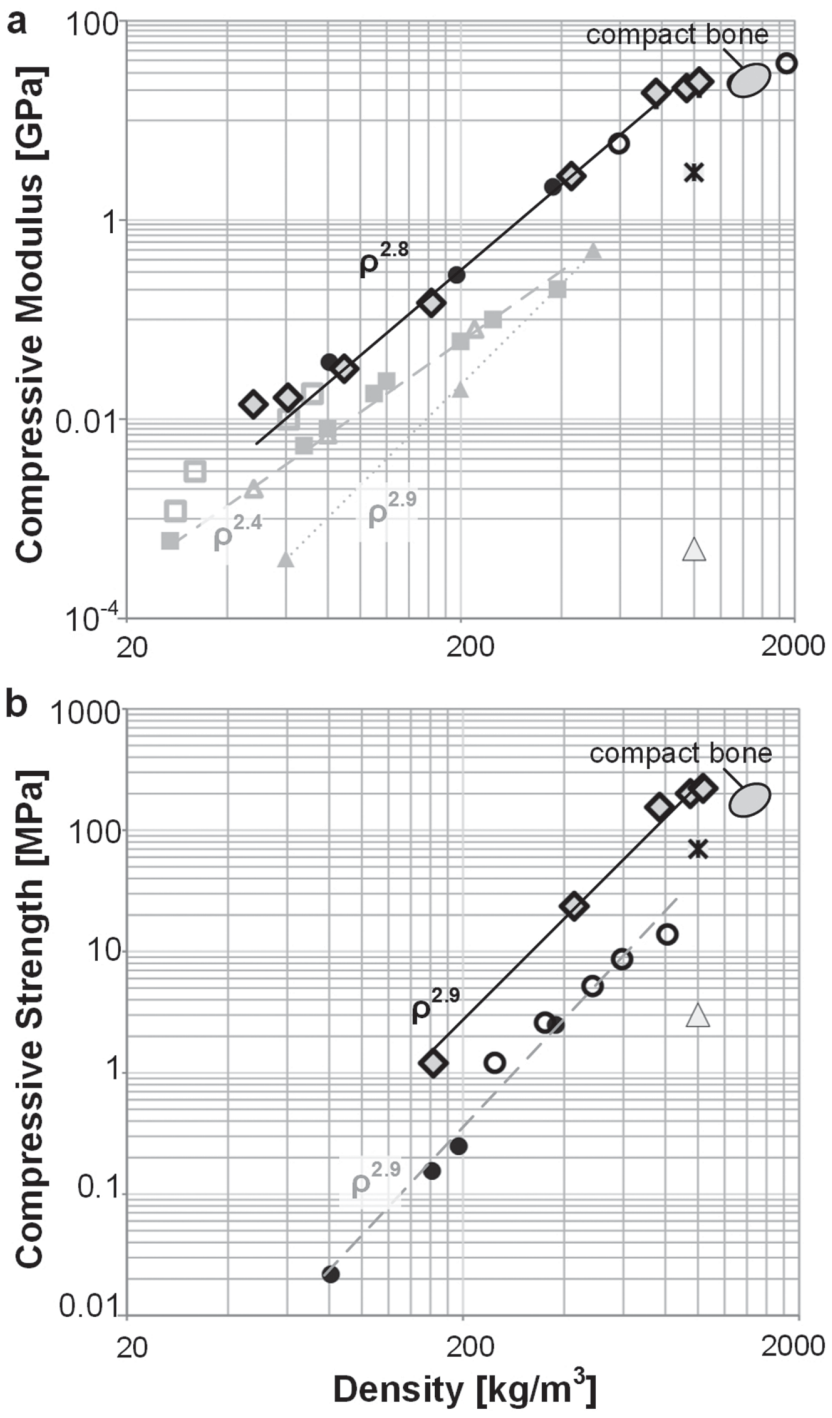

Figure 6. Measured power-law relationship between bulk density and compressive a) Young's modulus and b) strength of the $\mathrm{Al}_{2} \mathrm{O}_{3}$-CNT foams, compared to benchmark published and commercially available materials.

of the strut aspect ratio is independent of density. High modulus scaling power $(\mathrm{n})$, as shown by the $\mathrm{Al}_{2} \mathrm{O}_{3}$-CNT foams, is advantageous because we begin with low-density as grown CNTs and achieve a comparatively large increase in mechanical properties with increasing density. The controllability and interdependence of stiffness, strength, and toughness will certainly depend on the initial CNT density, diameter, and morphology, and moreover on the crystallinity and composition of the coating. Further study is warranted to understand these phenomena, and to engineer the mechanical energy storage and dissipation properties
In the present study, the scale of the materials tested was limited to the honeycomb films covering $\approx 1 \mathrm{~cm}^{2}$ area, and this area is determined by the size of the CVD furnace used for CNT growth. Nevertheless, the design principles of conformal coating and hierarchical patterning could be realized on much larger scales, such as within coatings of CNTs grown on woven micro-fibers or other porous frameworks. ${ }^{[33]}$ Moreover, emerging methods to pattern CNT growth catalyst using continuous printing methods such as laser printing, ${ }^{[34]}$ and machines for roll-to-roll CVD on metal foils, suggest that large-area coating and lamination of CNT forests will be possible in the future. Several schemes for high-speed continuous ALD have also been reported and are being commercialized. ${ }^{[35]}$

\section{Conclusion}

Conformal coating of CNT forests may serve as a scalable platform for the engineering and fabrication of hierarchical foams with nanoscale cell geometry. As demonstrated here, $\mathrm{Al}_{2} \mathrm{O}_{3}-\mathrm{CNT}$ foams made using lithographically patterned CNT microstructures followed by ALD coating show 1000-fold tunable Young's modulus, compressive strength, and toughness; and the scaling of Young's modulus over this wide range can be accurately predicted by the mechanics of beam deformation as informed by $\mathrm{X}$-ray characterization of the coating thickness. Moreover, the $\mathrm{Al}_{2} \mathrm{O}_{3}$-CNT foams have $\approx 10$-fold higher strength than commercial aluminum foams at the same density, as well as higher toughness due to the high ductility exhibited by the nanostructured ceramic coating. As a result, these foams may be suitable for filtration and shock absorption under high temperature and pressure conditions. We believe that capabilities to grow and coat CNTs in hierarchically microstructured geometries, on advanced fibers, and within porous materials, will enable realization of core-shell CNT-based foams in a wide range of macroscopic configurations. Future exploration of both ceramic and metallic coatings could enable new high-performance foams for structural applications as well as electrochemical energy storage materials where porosity and mechanical robustness are essential to high performance.

\section{Experimental Section}

CNT Growth: The catalyst for CNT forest growth is deposited on a (100) silicon wafer with $300 \mathrm{~nm}$ of thermally grown silicon dioxide. Photoresist (SPR220) is patterned by photolithography and developed, and then films of $10 \mathrm{~nm} \mathrm{Al} \mathrm{O}_{3}$ and $1 \mathrm{~nm}$ Fe are deposited by sputtering (Kurt J. Lesker PVD Lab 18). The photoresist is removed by performing two consecutive cycles ( 8 minutes each) of ultrasonication in acetone, followed by flushing with IPA. CNT growth is performed by thermal CVD in a quartz tube furnace (Thermo-Fisher Minimite, $22 \mathrm{~mm}$ inner diameter). Pieces of the patterned catalyst wafer are placed in the quartz tube and sealed, and then the furnace is flushed with $1000 \mathrm{sccm}$ $\mathrm{He}$ for 5 minutes. Then $100 / 400 \mathrm{sccm} \mathrm{H} \mathrm{H}_{2} / \mathrm{He}$ is flowed for 20 minutes; the temperature is ramped up to $775^{\circ} \mathrm{C}$ during the first 10 minutes and held for the next 10 minutes. For CNT growth, $100 \mathrm{sccm} \mathrm{C}_{2} \mathrm{H}_{4}$ is added to the gas mixture while the temperature is maintained at $775^{\circ} \mathrm{C}$. Once the growth step is complete, the furnace power is turned off, and the tube is flushed with $1000 \mathrm{sccm} \mathrm{He}$ until the furnace is below $100{ }^{\circ} \mathrm{C}$. The height of the CNT microstructures was controlled by the growth time, with the growth rate equaling approximately $50 \mu \mathrm{m} \mathrm{min}^{-1}$. 
ALD Coating: After growth, CNT micropillars were coated with alumina deposited via atomic layer deposition (ALD). The ALD process is performed in a low pressure CVD chamber (Oxford OpAl) at $300 \mathrm{mTorr}$ and $150{ }^{\circ} \mathrm{C}$ via alternating pulses of $\mathrm{Al}\left(\mathrm{CH}_{3}\right)_{3}$ and $\mathrm{H}_{2} \mathrm{O}$ with a purge between the pulses.

Mechanical Testing: Micropillars and perforated forests were tested in compression using a MTS Nanoindenter XP with flat diamond punch (100 $\mu \mathrm{m}$ diameter). In situ SEM compression tests were performed using a flat nanoindentation tip (100 $\mu \mathrm{m}$ diameter) within a custom built micromechanical test frame inside a SEM (FEI QUANTA ESEM), as described by Maschmann et al. [11]

$X$-ray Scattering: As-grown CNT micropillars as well as $\mathrm{Al}_{2} \mathrm{O}_{3}$ coated micropillars were mounted on a motorized sample stage in the Synchrotron X-ray beamline. TheEnergy of the X-ray beam used was $10+/-0.1 \mathrm{keV}$. Scattering patterns were collected on a 2D area detector. The size of the X-ray beam was controlled using a pair of motorized precision slits. More details of the experimental setup and the data analysis techniques are published in Bedewy et al. ${ }^{[19]}$

\section{Supporting Information}

Supporting Information is available from the Wiley Online Library or from the author.

\section{Acknowledgements}

This work was supported by the Air Force Office of Scientific Research (Young Investigator Program, FA9550-11-1-0089), the Office of Naval Research (Young Investigator Program, N000141210815), and the Defense Advanced Research Projects Agency (HR0011-10-C-0192). Support from DARPA was received under Agreement to NextGen Aeronautics, and any opinions, findings, and conclusions or recommendations expressed in this material do not necessarily reflect the views of NextGen Aeronautics and/ or DARPA. Microfabrication was performed at the Lurie Nanofabrication Facility (LNF), which is a member of the National Nanotechnology Infrastructure Network (NNIN); and electron microscopy was performed at the Michigan Electron Microbeam Analysis Laboratory (EMAL). SAXS was performed at the $\mathrm{G} 1$ beamline at the Cornell High Energy Synchrotron Source (CHESS) at Cornell University, which is supported by supported by the National Science Foundation and the National Institutes of Health under Grant DMR-0225180.

Note: the figures were changes slightly after initial online publication to make them clearer in grayscale format. The content of the figures was not changed.

Received: March 16, 2014

Revised: April 25, 2014

Published online: July 16, 2014

[1] a) R. Verdejo, R. Stämpfli, M. Alvarez-Lainez, S. Mourad, M. A. Rodriguez-Perez, P. A. Brühwiler, M. Shaffer, Composi. Sci. Technol. 2009, 69, 1564; b) H. N. G. Wadley, Adv. Engineering Mater. 2002, 4, 726; c) D. T. Queheillalt, D. D. Hass, D. J. Sypeck, H. N. Wadley, J. Mater. Res. 2001, 16, 1028.

[2] A. Barty, S. Marchesini, H. N. Chapman, C. Cui, M. R. Howells, D. A. Shapiro, A. M. Minor, J. C. H. Spence, U. Weierstall, J. Ilavsky, A. Noy, S. P. Hau-Riege, A. B. Artyukhin, T. Baumann, T. Willey, J. Stolken, T. van Buuren, J. H. Kinney, Phys. Rev. Lett. 2008, 101, 055501.

[3] L. J. Gibson, M. F. Ashby, Cellular Solids: Structure and Properties, Cambridge University Press, Cambridge, UK, 1999.

[4] R. O. Ritchie, Nat. Mater. 2011, 10,817.
[5] J.-H. Lee, L. Wang, M. C. Boyce, E. L. Thomas, Nano Lett. 2012, 12, 4392.

[6] T. A. Schaedler, A. J. Jacobsen, A. Torrents, A. E. Sorensen, J. Lian, J. R. Greer, L. Valdevit, W. B. Carter, Science 2011, 334.

[7] K. H. Kim, Y. Oh, M. F. Islam, Adv. Funct. Mater. 2013, 23, 377.

[8] R. M. German, Sintering Theory and Practice, Randall M. German, Wiley-VCH, Weinheim, Germany, 1996, 568.

[9] S. Tawfick, X. P. Deng, A. J. Hart, J. Lahann, Phys. Chem. Chem. Phys. 2010, 12, 4446.

[10] M. F. L. De Volder, S. H. Tawfick, R. H. Baughman, A. J. Hart, Science 2013, 339, 535.

[11] M. R. Maschmann, G. J. Ehlert, S. J. Park, D. Mollenhauer, B. Maruyama, A. J. Hart, J. W. Baur, Adv. Funct. Mater. 2012, 22.

[12] M. R. Maschmann, Q. Zhang, R. Wheeler, F. Du, L. Dai, J. Baur, ACS Appl. Mater. Interfaces 2011, 3, 648

[13] A. Y. Cao, P. L. Dickrell, W. G. Sawyer, M. N. Ghasemi-Nejhad, P. M. Ajayan, Science 2005, 310, 5752.

[14] a) S. Vaddiraju, H. I. Cebeci, K. K. Gleason, B. L. Wardle, ACS ACS Appl. Mater. Interfaces 2009, 1, 2565; b) O. Hildreth, B. Cola, S. Graham, C. P. Wong, J. Vacuum Sci. Technol. B: Microelectron. Nanometer Struct. 2012, 30, 03D101; b) C. F. Herrmann, F. H. Fabreguette, D. S. Finch, R. Geiss, S. M. George, Appl. Phys. Lett. 2005, 87, 123110.

[15] A. J. Hart, A. H. Slocum, J. Phys. Chem. B 2006, 110, 8250

[16] C. K. Devine, C. J. Oldham, J. S. Jur, B. Gong, G. N. Parsons, Langmuir 2011, 27, 14497.

[17] D. B. Farmer, R. G. Gordon, Nano Lett. 2006, 6, 699.

[18] a) B. N. Wang, R. D. Bennett, E. Verploegen, A. J. Hart, R. E. Cohen, J. Phys. Chem. C 2007, 111, 5859; b) M. Bedewy, E. Meshot, H. Guo, E. Verploegen, W. Lu, A. Hart, J. Phys. Chem. C 2009, 113, 20576; c) E. R. Meshot, D. L. Plata, S. Tawfick, Y. Y. Zhang, E. A. Verploegen, A. J. Hart, ACS Nano 2009, 3, 2477.

[19] M. Bedewy, E. R. Meshot, M. J. Reinker, A. J. Hart, ACS Nano 2011, $5,8974$.

[20] S. J. Park, A. J. Schmidt, M. Bedewy, A. John Hart, Phys. Chem. Chem. Phys. 2013, 15, 11511.

[21] M. R. Maschmann, G. J. Ehlert, S. J. Park, D. Mollenhauer, B. Maruyama, A. J. Hart, J. W. Baur, Adv. Funct. Mater. 2012, 22, 4686.

[22] a) B. I. Yakobson, C. J. Brabec, J. Bernholc, Phys. Rev. Lett. 1996, 76, 2511 ; b) A. Pantano, D. M. Parks, M. C. Boyce, J. Mech. Phys. Solids 2004, 52, 789

[23] E. R. Meshot, M. Bedewy, K. M. Lyons, A. R. Woll, K. A. Juggernauth, S. Tawfick, A. J. Hart, Nanoscale 2010, 2, 896

[24] M. M. J. Treacy, T. W. Ebbesen, J. M. Gibson, Nature 1996, 381, 6584

[25] M. K. Tripp, C. Stampfer, D. C. Miller, T. Helbling, C. F. Hermann, C. Hierold, K. Gall, S. M. George, V. M. Bright, Sens. Actuators A 2006, 130, 419

[26] E. Andrews, W. Sanders, L. J. Gibson, Mater. Sci. Engineering: A. $1999,270,113$

[27] H. Cebeci, R. G. de Villoria, A. J. Hart, B. L. Wardle, Composi. Sci. Technol. 2009, 69, 2649.

[28] L. J. Gibson, M. F. Ashby, Proc. R. Soc. 1982, 382, 43.

[29] HexWeb Honeycomb Attributes and Propertieshttp://www.hexcel. com/Resources/DataSheets/Brochure-Data-Sheets/Honeycomb_ Attributes_and_Properties.pdf (accessed August 2013)

[30] M. A. Worsley, S. O. Kucheyev, J. H. Satcher, Jr., A. V. Hamza, T. F. Baumann, Appl. Phys. Lett. 2009, 94, 7.

[31] J. Zou, J. Liu, A. S. Karakoti, A. Kumar, D. Joung, Q. Li, S. I. Khondaker, S. Seal, L. Zhai, ACS Nano 2010, 412.

[32] T. M. Tillotson, L. W. Hrubesh, J. Non-Cryst. Solids 1992, 145, 44.

[33] N. Yamamoto, A. J. Hart, E. J. Garcia, S. S. Wicks, H. M. Duong, A. H. Slocum, B. L. Wardle, Carbon 2009, 47, 551

[34] E. S. Polsen, A. G. Stevens, A. J. Hart, ACS Appl. Mater. Interfaces 2013, 5, 3656

[35] G. N. Parsons, S. M. George, M. Knez, MRS Bull. 2011, 36, 865 